\title{
R \& D, Technology Imports and Innovation Capacity-Evidence from High-Tech Industry of China
}

\author{
Ming Dai, Yi Chen \\ School of Economics, Jinan University, Guangzhou, China \\ Email: bofeng1004@126.com, sugarman128@126.com
}

Received 30 December 2015; accepted 19 January 2016; published 22 January 2016

Copyright (C) 2016 by authors and Scientific Research Publishing Inc.

This work is licensed under the Creative Commons Attribution International License (CC BY). http://creativecommons.org/licenses/by/4.0/

(c) (i) Open Access

\begin{abstract}
The paper is dedicated to probing into the effects of $R \& D$, foreign and domestic technology imports on innovation capacity by using the province-level panel data of high-tech industry from 1999 to 2012 . The analysis shows that $R \& D$, foreign technology imports do have positive influences on improving innovation capacity while the effects of domestic technology transfer are not significant and $R \&$ D do positive effects on assimilating foreign and domestic technology imports. The relationships among $R \& D$, foreign and domestic technology and innovation capacity also take on different patterns in different regions. Technology imports' influences on improving innovation capacity are not significant in the middle and west region. Each region should propose specific incentives for innovation to enhance regional innovation capability.
\end{abstract}

\section{Keywords}

R \& D, Technology Import, Innovation Capacity, High-Tech Industry

\section{Introduction}

Since 1980s, the high-tech industry has become an important source of economic growth in every country. As a symbol of comprehensive national power and the level of technological advancement, the high-tech sector plays an important role in the economic growth of China in the new era. Technological innovation, as a key enabler of high-tech industry, can influence the whole competitiveness strengthening of high-tech industry and the state innovation system to a large extent. How to improve the innovation ability of high-tech industry also becomes an urgent problem to solve.

Domestic scholars' researches on the innovation ability of high-tech industry mainly focus on the evaluation 
of innovation ability, the research on innovation efficiency and the influence of specific factors on it. Gao Dahong (2010) [1] has analyzed and sorted the factors that influence the innovation output of high-tech industry of our country and the five sub-industries by making use of grey correlation model and related index of innovation ability. Zhao Yulin and Cheng Ping (2013) [2] have built the evaluation index of the innovation ability of hightech industry and have dynamically evaluated the innovation ability of every province of our country by principal component analysis concluding that there are serious regional differences for the innovation ability of high-tech industry between different regions and the gap is still widening. Han Jing (2010) [3] has demonstrated the innovation efficiency of high-tech industry of our country by using stochastic frontier analysis method. Wang Wei (2011) [4] has evaluated the innovation ability of high-tech industry of every province of China as well as the development situation of the high-tech industry all over China by adopting data envelopment analysis. Using provincial panel data, Yang Xiangyang et al. (2013) [5] and others have investigated innovation efficiency status of two sub-stages during innovation process of high-tech industry by applying Malmquist index method. All above researches have analyzed the influential factors of innovation efficiency and innovation ability from different aspects but barely mentioned effective approaches to enhance innovation ability of high-tech industry of our country while the research on this issue has more realistic significance.

Based on research and development of high technology and the production, high-tech industry has unceasingly transformed the high technology and knowledge into the industry of new products and new processing; In the process of its progress and development, the enhancement of innovation ability owns an important meaning and has determined the development prospects of industries. In the context of economic globalization, if a country wants to achieve technological progress and innovation of industries, it is also an important way for it to completely absorb and effectively make full use of advanced technology and experiences both at home and abroad except relying on local research and development. Generally, domestic technology transfer will rely on the way of directly purchasing of it and there are two kinds of introduction ways of foreign technology, one of which is direct introduction of foreign advanced technology with indirectly spilling over advanced technology to the host country through demonstration effect brought by FDI and competition effect as the other way. As for the aspect of the relationship between the introduction of foreign technology and innovation ability, the vast majority of literatures have focused on the influence of the spilling over of FDI technology upon the enhancement of innovation ability. Making use of panel data of sub-industries, Sha Wenbing and Sun Jun (2010) [6] have studied the influence of spilling over FDI knowledge upon the innovation ability of China's high-tech industry, considering that the research and development activities of foreign enterprises have promoted the enhancement of innovation ability of domestic enterprises to a certain extent. Jing Pan and Zhang Jiarong (2012) [7] have studied the influence of the research and development investments of multinational companies in China upon the innovation ability of China's high-tech industry from four aspects.

Based on above studies, we can know that FDI has a certain influence upon innovation ability of high-tech industry but the influence of technology imports upon innovation ability of high-tech industry remains to be studied; Using the panel data of high-tech industry of 26 provinces in China from 1999 to 2012, this paper has carried out an empirical study on independent research and development as well as the relationships between the domestic technology transfer and foreign technology imports and the innovation ability and has analyzed the result of the study with finally putting forwards the corresponding countermeasures and recommendations.

\section{Model and Data}

\subsection{Model Structure}

Cobb-Douglas function is the most commonly used form of production function, which can be shown as follows:

$$
Q_{i t}=A_{i t} C_{i t}^{\alpha} L_{i t}^{\beta}
$$

where $Q_{i t}, C_{i t}$ and $L_{i t}$ respectively represent the output of the region $i$ in the year $t$, the material capital investment and the human capital investment. $\alpha$ and $\beta$ respectively represent the output flexibility of material capital investment and the output flexibility of human capital investment. $A_{i t}$ represents total factor productivity, meaning all other factors influencing the output except material capital investment and human capital investment. 
In the view of investment and output, innovation activities of enterprises can be shown in terms of production function, where the innovation ability can be known as the output form of innovation activities of enterprises. However, in the specific analysis, it is usually very difficult to find an index to directly measure the innovation ability. The existed methods to measure innovation ability are divided into two categories: One is selecting the substitute variable of innovation ability; Xian Guoming and Yan Bing (2005) [8] as well as Li Xuedong (2011) [9] have selected three output indexes, which are patent application amount, new products and the growth rate of technical progress, as substitute variables and have investigated the influence of FDI upon enterprise innovation; The other is establishing evaluation index system for measuring innovation ability to comprehensively evaluate the innovation ability of enterprises from many aspects, such as the investment, the output and so on; Zhang Huasheng (2006) [10] has established an analytical framework to carry out the empirical analysis of innovation ability of manufacturing industry.

Starting from building a production function that can reflect the innovative activities of enterprises, this paper has analyzed the influence of different technical improvement ways upon the innovation ability. Therefore, continuing to use Xian Guoming and Yan Bing's (2008) [11] processing method, taking the amount of patent applications as the measurement index of innovation ability, this paper has built the following production function on the basis of C-D function:

$$
\operatorname{PAT}_{i t}=F\left(A_{i t}, R D E_{i t}, L_{i t}\right)
$$

PAT is the total amount of patent applications in Equation (2); $R D E$ is the expenditures for the research and experimental development ( $\mathrm{R} \& \mathrm{D}$ ) and $L$ is the equivalent for full attendance of $\mathrm{R} \& \mathrm{D}$ staff, respectively representing the output and investment of innovation activities. Representing the total factor productivity, $A$ refers to all other factors affecting the innovation ability except R \& D expenditure and the equivalent for full attendance of R \& D staff. In the innovation activities of enterprises, not only influenced by the independent research accumulated in previous "learning by doing", the improvement of innovation ability of total factor productivity may also be promoted by the introduction of domestic and foreign technology. Therefore, we define the total factor productivity as:

$$
A_{i t}=A \mathrm{e}^{f\left(R D S_{i t-1} F T I_{i t-1} D T P_{i t-1} C A P_{i t} S I Z E_{i t}\right)+b_{i}}
$$

$R D S$ is the R \& D expenditure stock in Equation (3); FTI is the foreign technology imports stock; DTP is the domestic technology transfer stock; CAP is the stock of material investment and SIZE is the scale of an enterprise. Because the influence of all innovation activities of enterprises upon the innovation ability has a long-term characteristic, thus the expenditure stocks of all technology activities are considered to be added in the model. Additionally, various innovation activities of enterprises in the current period will be affected by all previous technology activities, so in Equation (3), the innovation ability in period $t$ is the function of the technology activities' stock in period $t$-1. Meanwhile, the innovation activities cannot be carried out without the investment of material capital and the scale difference may also influence the improvement of enterprises' innovation ability. These two influential factors are also included in the model as controlled variables. $A$ is a constant term and $b_{i}$ represents the observed individual effect.

Bring Equation (3) into Equation (2) and take logarithm on both sides of the equation, implying that:

$$
\begin{aligned}
\ln P A T_{i t}= & \ln A+\alpha \ln R D E_{i t}+\beta \ln L_{i t}+\gamma_{1} \ln R D S_{i t-1}+\gamma_{2} \ln F T I_{i t-1} \\
& +\gamma_{3} \ln D T P_{i t-1}+\gamma_{4} \ln C A P_{i t}+\gamma_{5} \ln S I Z E_{i t}+b_{i}+c_{i t}
\end{aligned}
$$

Equation (4) determines the basic form of the measurement model of the paper; $b_{i}$ reflects individual effect; Parameters $\alpha$ and $\beta$ respectively are the $\mathrm{R} \& \mathrm{D}$ expenditure of innovation ability and the flexibility of the investment of technical personnel; $\gamma_{1}, \gamma_{2}$ and $\gamma_{3}$ respectively represent R \& D expenditure stock, the foreign technology imports stock and the output flexibility of innovation ability of domestic technology transfer stock; $\gamma_{4}$ and $\gamma_{5}$ reflect the influence of material investment stock and enterprises' scale upon innovation ability.

\subsection{Variable Selection and Data Sources}

2.2.1. Stock of R \& D Expenditure, Foreign Technology Imports and Domestic Technology Transfer As factors of influence the enterprise innovation ability, R \& D spending and technology at home and abroad all use the perpetual inventory method to measure. Stock of $\mathrm{R} \& \mathrm{D}$ spending, for example, if the depreciation rate is 
$\delta$, the calculation formula is:

$$
R D S_{i t}=R D E_{i t}-(1-\delta) R D S_{i t-1}
$$

Firstly, determine the initial stock and the depreciation rate. Set before the sample period (before 1999) all R \& D spending at an average growth rate of $g$, base stock of R \& D expenditure can be expressed as:

$$
R D S_{i 0}=R D E_{i 0}(1+g) /(g+\delta)
$$

According to the measurement of Wu Yanbing, the average annual growth rate of R \& D expenditure in our country is $5 \%$ and R \& D inventory depreciation is set up at the rate of $15 \%$, namely the base stock of R \& D spending is 5.25 times of the base period of $\mathrm{R} \& \mathrm{D}$ expenditure. This paper uses the above methods to measure the expenditure that involved in the enterprise technical activities. The depreciation rate of foreign technology imports stock and domestic technology transfer stock the depreciation rates are $15 \%$ and $25 \%$ and also set the average annual growth rate as $5 \%$ about the foreign technology imports stock and domestic technology transfer stock before the sample. Finally, the technical activities spending are deflated into the actual value. Using the price index of investment in fixed assets in 1998 as the base period and making adjustment about the stock of R \& D expenditure, technology imports and domestic technology transfer. So we can reach a conclusion that the average value about the spending of the high-tech industry in 26 provinces from 1999 to 2012.

\subsubsection{R \& D Expenditure, Material input Stock and Enterprise Size}

In the name of the $\mathrm{R} \& \mathrm{D}$ expenses in different provinces and considering the volatility of price and using price index of investment about the fixed assets to deflate for its actual value. The material input of the enterprise will have an important influence on enterprise's innovation activities in the long run. Material input is generally measured by fixed assets and to estimate the investment of fixed assets in the stock of high-tech industry also use the perpetual inventory method. For depreciation rate and base stock can reference the methods of Zhang Jun et al. (2004) [12]. They set the depreciation rate of fixed asset investment is $9.6 \%$ and assuming the base stock is 10 times the value of fixed assets and finally use the price index of investment in fixed assets to deflate for actual value.

There is a lack of unified standard to measure the enterprise size. Zhou Li'an (2005) [13] uses the formally hired workers in the enterprises in a region and the average output as the two indexes to measure the proxy variables of enterprise size. This paper continues to use this kind of treatment method to consider the availability of data and it also uses the average income of the high-tech industry as a measurement of the enterprise size. The number of the provincial high-tech industry companies and the main business income are all derived from the China statistical yearbook of science and technology.

In this paper, the data of empirical model all derived from the China statistics yearbook on high technology industry and China statistical yearbook. Patent filings, R \& D expenditure, technology import spending at home and abroad and material capital input data are derived from the China statistics yearbook on high technology industry. To avoid price fluctuations on the impact of variables, using the corresponding price index of different provinces to translate the nominal value for the actual value. And the involved price index of the investment in fixed assets and the price index of industrial products are from the China statistical yearbook and there is a lack of two years price index of investment in fixed assets in Guangdong province, with the nation's price index of investment in fixed assets instead. In China's 31 provinces, the data of high technology industry in Inner Mongolia, Hainan, Qinghai, Tibet and Xinjiang are partially missing and they are excluded from the sample. R \& D related data statistics of high technology industry in China is later and can only get the statistics after 1998. At the same time, (4) involved in the lag issue of stock of the technical activities of spending, so the time series of analyzing samples is from 1999 to 2012. In the end, this paper selects the panel data of high technology industry as the econometric model samples in 26 provinces of China from 1999 to 2012.

\section{The Estimated Results and Discussion}

\subsection{Basic Estimation Results}

Measurement model in this paper is Equation (4). For the possible problem in its direct return is that the control variables may be related to R \& D investment and enterprise in the process of the technological progress of activities and the spending during the various technical progresses may also be relevant. And the multicollinearity 
problems will make the coefficient estimator can not accurately reflect and explain the influence of variables to be explained and to avoid this kind of influence as much as possible. This article adopts the method of stepwise regression. For each step regression model selecting, all depending on the fixed effects and the Hausman test results of the random effects.

As can be seen from the estimated results in Table 1, the enterprise R \& D funds and personnel input as important input variables and for the influence of innovation ability is significant. Join the enterprise R \& D expenditure stock, foreign technology imports stock and domestic technology transfer stock in Columns (3) to (5), the results show that the domestic technology transfer stock coefficient estimate is not significant. But according to the purpose in this paper, spending of the enterprise technology activities all have important economic significance, therefore should not eliminate variables $\ln D T P$. Column (6) included all explanatory variables in the econometric model and can be seen from the estimated results that the inputs of enterprise R \& D have a significant impact on innovation ability. In the kinds of activities about enterprise technology, the effects of the R \& D expenditure stock on innovation ability has the largest influence and it followed by the foreign technology imports stock. And the domestic technology transfer stock has no significant impact on the innovation ability. The larger size of enterprise and capital stock also has positive impact on the improvement of enterprise innovation ability.

According to the estimated results of Equation (4), the stock of innovation ability for enterprise R \& D expenditure elasticity is 0.33 and it is higher than 0.12 , the elasticity of the foreign technology import stock. It shows that to some extent on the basis of "learning by doing" that accumulated independent research and development ability of enterprise innovation ability promotion effect is superior to the technology import directly, therefore, independent research and development is the most direct way to promote the accumulation of enterprise innovation ability. But when affirms the dominant position of independent research and development, we should also pay attention to technology transfer for the significant role of cultivating the ability of technology

Table 1. Estimation results: selecting some explanatory variables based on Equation (4).

\begin{tabular}{|c|c|c|c|c|c|c|}
\hline Variables & (1) $\mathrm{FE}$ & (2) $\mathrm{FE}$ & (3) $\mathrm{FE}$ & (4) $\mathrm{FE}$ & (5) $\mathrm{FE}$ & (6) FE \\
\hline CONS & $\begin{array}{c}-17.126^{* * *} \\
(-11.80)\end{array}$ & $\begin{array}{c}-15.556^{* * *} \\
(-11.50)\end{array}$ & $\begin{array}{c}-16.224^{* * *} \\
(-12.06)\end{array}$ & $\begin{array}{c}-16.879^{* * * *} \\
(-11.68)\end{array}$ & $\begin{array}{c}-15.556^{* * *} \\
(-11.57)\end{array}$ & $\begin{array}{l}-17.226^{* *+} \\
(-11.88)\end{array}$ \\
\hline $\ln R D S$ & & & $\begin{array}{c}0.345^{* * * *} \\
(3.13)\end{array}$ & & & $\begin{array}{c}0.360^{* * * *} \\
(2.73)\end{array}$ \\
\hline $\ln F T I$ & & & & $\begin{array}{l}0.134^{* *} \\
(2.41)\end{array}$ & & $\begin{array}{c}0.115^{* * *} \\
(2.73)\end{array}$ \\
\hline $\ln D T P$ & & & & & $\begin{array}{l}0.040 \\
(0.73)\end{array}$ & $\begin{array}{l}-0.080 \\
(-1.24)\end{array}$ \\
\hline $\ln C A P$ & & $\begin{array}{c}0.470^{* * *} \\
(7.17)\end{array}$ & $\begin{array}{c}0.394^{* * *} \\
(5.70)\end{array}$ & $\begin{array}{c}0.433^{* * *} \\
(6.50)\end{array}$ & $\begin{array}{c}0.457^{* * *} \\
(6.72)\end{array}$ & $\begin{array}{c}0.391^{* * *} \\
(5.62)\end{array}$ \\
\hline $\ln S I Z E$ & & $\begin{array}{c}0.420^{* * * *} \\
(3.33)\end{array}$ & $\begin{array}{l}0.311^{* * *} \\
(2.53)\end{array}$ & $\begin{array}{c}0.450^{* * * *} \\
(3.70)\end{array}$ & $\begin{array}{c}0.398^{* * * *} \\
(3.28)\end{array}$ & $\begin{array}{l}0.364^{* * * *} \\
(2.88)\end{array}$ \\
\hline $\ln R D E$ & $\begin{array}{l}1.007^{* * * *} \\
(16.87)\end{array}$ & $\begin{array}{c}0.517^{* * *} \\
(6.40)\end{array}$ & $\begin{array}{c}0.370^{* * * *} \\
(4.03)\end{array}$ & $\begin{array}{c}0.470^{* * * *} \\
(5.75)\end{array}$ & $\begin{array}{c}0.502^{* * *} \\
(6.12)\end{array}$ & $\begin{array}{c}0.306^{* * * *} \\
(3.93)\end{array}$ \\
\hline $\ln L$ & $\begin{array}{c}0.994^{* * *} \\
(6.46)\end{array}$ & $\begin{array}{c}0.421^{* * * *} \\
(2.72)\end{array}$ & $\begin{array}{c}0.430^{* * * *} \\
(2.81)\end{array}$ & $\begin{array}{l}0.463^{* * * *} \\
(2.99)\end{array}$ & $\begin{array}{c}0.437^{* * *} \\
(2.75)\end{array}$ & $\begin{array}{c}0.454^{* * * *} \\
(3.93)\end{array}$ \\
\hline Adj. $R^{2}$ & 0.842 & 0.869 & 0.873 & 0.871 & 0.869 & 0.874 \\
\hline Prob. F & 0.000 & 0.00 & 0.00 & 0.00 & 0.00 & 0.00 \\
\hline
\end{tabular}

Note: FE, fixed effects model; ${ }^{*}$ statistically significant at the $10 \%$ level; ${ }^{* *}$ statistically significant at the $5 \%$ level; ${ }^{* * *}$ statistically significant at the $1 \%$ level. 
innovation. While there are technical barriers during the process of directly introducing the foreign technology may not be able to import the advanced technology of developed countries, but as long as the technology import is suitable for our country and it also helps to narrow the technology gap between our country and developed countries. And compared to the independent research and development, the technology import has the characteristics of low risk and can also reduce the uncertainty and blindness in the process of independent research and development. Compared with the foreign technology imports, domestic technology transfer stock for enterprise innovation ability promotion effect is not significant, this may be due to the big gap between the technology level of domestic enterprises and overseas technical level and it may also be the concept of maintaining their own technological advantages for the domestic enterprises, so it will not transfer its truly technology that is the core of the competitiveness of enterprises. So the domestic technology cannot be directly promoted the innovation ability.

\subsection{The Absorptive Capacity of R \& D and Innovation Ability}

In order to analyze the relationship between the domestic technology transfer stock and R \& D. On the basis of the Equation (4), the introduction of domestic technology transfer stock and cross terms of R \& D expenditure and thus build the following econometric model:

$$
\begin{aligned}
\ln P A T_{i t}= & c_{1}+f_{i}+\alpha \ln R D E_{i t}+\beta \ln L_{i t}+\lambda_{1} \ln R D S_{i t-1}+\lambda_{2} \ln F T I_{i t-1}+\lambda_{3} \ln D T P_{i t-1} \\
& +\lambda_{4} \ln C A P_{i t}+\lambda_{5} \ln S I Z E_{i t}+\lambda_{6} \ln R D E_{i t} \times \ln D T P_{i t-1}+\mu_{i t}
\end{aligned}
$$

In Equation (7), $c_{1}$ as the constant term, $f_{i}$ for individual effects and $\mu_{i t}$ as random items. On the basis of (7) to introduce foreign technology import stock continuously and the cross terms of R \& D expenditure, if the overlapping coefficient is positive and then it indicates that there exists complementary effect between them. The model can be expressed as the Equation (8) through adjustment:

$$
\begin{aligned}
\ln P A T_{i t}= & c_{2}+v_{i}+\alpha \ln R D E_{i t}+\beta \ln L_{i t}+\varphi_{1} \ln R D S_{i t-1}+\varphi_{2} \ln F T I_{i t-1}+\varphi_{3} \ln D T P_{i t-1}+\varphi_{4} \ln C A P_{i t} \\
& +\varphi_{5} \ln S I Z E_{i t}+\varphi_{6} \ln R D E_{i t} \times \ln D T P_{i t-1}+\varphi_{7} \ln R D E_{i t} \times \ln F T I_{i t-1}+\mu_{i t}
\end{aligned}
$$

In (8), $c_{2}$ for the constant term, $v_{i}$ for individual effects, $\mu_{i t}$ as random items. Estimated results of the (8) are shown in Table 2.

The estimated results of Table 3 shows that the cross of $\ln R D E \times \ln D T P$ is significantly positive and it means that although domestic technology transfer can't directly promote the ability of the enterprise innovation, through independent research and development of enterprises can indirectly promote the innovation ability of ascension. The coefficient of $\ln F T I, \ln L, \ln R D E \times \ln F T I$ was not significant and combined with the regression results in Table 2, the coefficient was not significant may likely to be caused by cross terms are introduced to the result of multicollinearity. Coefficient estimate symbol of $\ln D T P$ and $\ln R D E$ does not accord with the expected because of the cross term $\ln R D E \times \ln D T P$ contained in (8). In the Column (2), remove the cross term $\ln R D E \times \ln D T P$ and the not significant variable $\ln L$, the results showed that $\ln R D E \times \ln F T I$ by significance test under $1 \%$ confidence level, the other variable symbols did not change. Hu et al. (2005) [14] use Chinese enterprise data found that there is a complementary relationship with domestic and international technology transfer of R \& D. Independent research and development not only can directly promoted the promotion of the enterprise's innovation ability and it also has positive influence on imitating, digesting and absorbing foreign and domestic technology.

\subsection{The Regional Differences of the Innovation Ability}

There is a big difference among economic basis and the technical level in eastern, central and western regions in China and there is also a large imbalance between regional research and development ability and technology imports and transfer, independent research and development and technology imports and transfer for the influence of the innovation ability may also show different characteristics. In order to analyze the regional differences, this article subdivided into features of the 26 provinces into three samples and at the basic model of (4), the results as shown in Table 3.

Estimating result from Table 3 shows that domestic technology transfer spending for eastern and central all 
Table 2. Estimation results: based on (8).

\begin{tabular}{|c|c|c|}
\hline Variables & (1) $\mathrm{FE}$ & (2) FE \\
\hline \multirow{2}{*}{ CONS } & 0.457 & $-4.429^{* * *}$ \\
\hline & $(-0.91)$ & $(-4.09)$ \\
\hline \multirow{2}{*}{$\ln R D S$} & $0.230^{* *}$ & $0.221^{* *}$ \\
\hline & (2.04) & (1.94) \\
\hline \multirow{2}{*}{$\ln F T I$} & -0.215 & $-0.862^{* * *}$ \\
\hline & $(-0.84)$ & $(-6.53)$ \\
\hline \multirow{2}{*}{$\ln D T P$} & $-0.740^{* * *}$ & -0.02 \\
\hline & $(-3.37)$ & $(-0.36)$ \\
\hline \multirow{2}{*}{$\ln C A P$} & $0.393^{* * * *}$ & $0.412^{* * * *}$ \\
\hline & $(6.09)$ & $(6.71)$ \\
\hline \multirow{2}{*}{$\ln S I Z E$} & $0.557^{* * *}$ & $0.586^{* * *}$ \\
\hline & (4.34) & (5.038) \\
\hline \multirow{2}{*}{$\ln R D E$} & $-0.553^{* * *}$ & $-0.612^{* * *}$ \\
\hline & $(-3.42)$ & $(-4.09)$ \\
\hline \multirow{2}{*}{$\ln L$} & -0.252 & \\
\hline & $(-1.54)$ & \\
\hline \multirow{2}{*}{$\ln R D E \times \ln D T P$} & $0.078^{* * *}$ & \\
\hline & (3.42) & \\
\hline \multirow{2}{*}{$\ln R D E \times \ln F T I$} & 0.336 & $0.102^{* * *}$ \\
\hline & (1.45) & (8.08) \\
\hline Adj. $R^{2}$ & 0.895 & 0.892 \\
\hline Prob.F & 0.000 & 0.000 \\
\hline
\end{tabular}

Table 3. The measurement results of innovation capability among the eastern, central and western regions.

\begin{tabular}{cccc}
\hline Variables & Eastern (FE) & Central (FE) & Western (FE) \\
\hline CONS & $-17.320^{* * * *}$ & $-19.913^{* * * *}$ & $(-5.64)$ \\
& $(-9.94)$ & $(-6.36)$ & -0.002 \\
$\ln R D S$ & $0.865^{* * * * *}$ & $0.772^{* * *}$ & $(-0.90)$ \\
& $(5.39)$ & $(2.44)$ & 0.045 \\
$\ln$ FTI & $0.344^{* * *}$ & -0.103 & $(0.42)$ \\
& $(3.79)$ & $(-1.07)$ & $-0.203^{* * *}$ \\
$\ln D T P$ & 0.136 & 0.151 & $(-1.93)$ \\
& $(1.23)$ & $(1.35)$ & $0.493^{* * *}$ \\
$\ln C A P$ & 0.042 & 0.301 & $(4.19)$ \\
& $(0.44)$ & $(2.16)$ & $0.712^{* * *}$ \\
$\ln S I Z E$ & $0.308^{* * *}$ & -0.490 & $(3.12)$ \\
& $(1.97)$ & $(-1.59)$ & $0.531^{* * *}$ \\
$\ln R D E$ & $0.289^{* *}$ & $0.505^{* * *}$ & $(2.97)$ \\
$\ln L$ & $(2.15)$ & $(3.32)$ & $-0.552^{* * *}$ \\
Adj.R & 0.046 & $0.944^{* *}$ & $(-3.12)$ \\
Prob.F & $(0.23)$ & $(2.17)$ & 0.796 \\
& 0.921 & 0.891 & 0.000 \\
\hline
\end{tabular}


did not significantly influence the innovation ability of ascension and this also obtained the results when using the same sample. R \& D spending and foreign technology import spending and stock of R \& D spending for the influence of innovation ability in all areas present a bigger difference: in the eastern region, R \& D expenditure, foreign technology introduction and R \& D spending stock for regional innovation ability showed a significant positive impact on the ascension; In the central region, R \& D expenditure stock and R \& D expenditure have a significant positive effect on promoting regional innovation ability. However, foreign technology import spending has no significant effect to the promotion of innovation ability; Only R \& D expenditure in the western region has significant positive effect on promoting innovation capacity and it's important to note that domestic technology purchased coefficient showed significant negative impact on the innovation ability and this maybe because in the western region for the transfer of the lack of domestic technology digestion and absorption ability can't play the role of the purchase technology.

Features of this three areas show the main reason of the differences is that the development level and degree of opening in eastern region economic to the outside world are significantly higher than the central and western areas, which created the conditions for the introduction of foreign technology. And the enterprise in eastern part is better in the process of independent research and development experience and it also makes the foreign technology be fully digested and absorbed and it ultimately plays a better role in ascending enterprise innovation in eastern. For the Midwest, in the process of improving the innovation ability, independent research and development played an irreplaceable role and at the same time of continuing to pay emphasis on independent research and development we should also create conditions for the introduction of complementary technology so as to fill the blank of the existing technology.

\section{Conclusions and Policy Suggestions}

Through inter-provincial panel data of high-tech industry, this paper analyzes the independent research and development also analyzes the effect of the introduction of international technology to enhance innovation capability. Results show that R \& D spending and the introduced foreign technology for the ability of the enterprise innovation all have significant positive effect, while the influence on enterprise innovation ability is not significant from the aspect of the purchase of domestic technology. Meanwhile, the company's independent research and development will not only directly contribute to the promotion of innovation, its digestion and absorption of technology at home and abroad also have a positive impact. With the deepening of market-oriented reform in China, independent research and development should be further strengthened in its leading position in enterprise innovation capability. And to create a favorable external environment and strengthen the protection of intellectual property rights for enterprise innovation and R \& D activities have an important significance. In addition, on the one hand, we should incentivize independent research and development but on the other hand we should also pay attention to the introduction of technology which can promote the innovation capacity. Through encouraging the integration of independent research and development and technology, enhancing their innovation capability of enterprises and continuously promoting technological progress, the innovation capability can be improved.

At the same time of continuously advancing our innovation capability, we should also pay attention to regional differences. This paper analyzes and shows that the introduction of technology in the Midwest does not have a significant role in promoting the innovation capacity. At this stage, during the process of improving the innovation capability through independent research and development in the central, east and west, it should concern about the introduction of technology to strengthen the self-development and accumulation of the self-research, adjust measures to local conditions, put forward corresponding innovation incentives and comprehensively enhance the regional innovation ability. So, the development of regional economy can be balanced.

\section{References}

[1] Gao, D. (2010) The Analysis of High-Tech Industry Innovation Capability Based on Gray Correlation. Science \& Technology Management Research, 16, 8-11, 15.

[2] Zhao, Y.L. and Cheng, P. (2013) An Empirical Analysis on Technological Innovation Capacity of Hi-Tech Industry on Provincial Scales in China. Journal of Business Economics, 1, 77-85.

[3] Han, J. (2010) An Empirical Analysis on China'S High-Technology Industry Innovation Efficiency Based on SFA. Studies in Science of Science, 3, 467-472. 
[4] Wang, W. (2011) Modified Data Envelopment Analysis Model for Technological Innovation Efficiency of China's Hi-Tech Industry. Science \& Technology Progress and Policy, 17, 119-124.

[5] Yang, X.Y., Tong, X.L. and Li, N. (2013) Study on Innovation Efficiency of High-Tech Industry in China Based on Two Stages-Empirical Analysis of Provincial Panel Data. East China Economic Management, 1, 84-88.

[6] Sha, W.B. and Sun, J. (2010) The Influence of FDI Knowledge Spillovers on the Innovative Capacity of Chinese Hi-Tech Industry—Test based on Sub-Industry Panel Data. Economist, 11, 75-79.

[7] Pan, J. and Zhang, J. (2012) The Empirical Study on the Influence of Multinational Corporations' R \& D Investment on China’s High-Tech Industry Innovation Ability. Forum on Science \& Technology in China, 1, 30-36.

[8] Xian, G. and Yan, B. (2005) The Spill-Over Effect of FDI on China's Innovation Capacity. World Economy, 10, 18-25, 80.

[9] Li, X.D. (2011) The Empirical Study of Innovation of Chinese High-Tech Industry-Based on Different Characters of Dependent Variables. Science \& Technology Management Research, 3, 4-8.

[10] Zhang, H.S. (2006) The Analyses of Technological Innovation Capability of China's Manufacturing Industries. China Soft Science, 4, 15-23.

[11] Wu, Y.B. (2008) Indigenous R \& D, Technology Imports and Productivity: Evidence from Industries across Regions of China. Economic Research Journal, 8, 51-64.

[12] Zhang, J., Wu, G.Y. and Zhang, J.P. (2004) The Estimation of China’s provincial capital stock: 1952-2000. Economic Research Journal, 10, 35-44.

[13] Zhou, L.A. and Luo, K. (2005) Firm Size and Innovation: Evidence from China’s Province-Level Data. China Economic Quarterly, 2, 623-638.

[14] Jefferson, G.H., Qian, J.C. and Hu, A.G.Z. (2005) R \& D and Technology Transfer: Firm-Level Evidence from Chinese Industry. Review of Economics \& Statistics, 87, 780-786. http://dx.doi.org/10.1162/003465305775098143 